\title{
Pharyngoesophageal perforation during introduction of an echoendoscope treated with a fully covered self-expandable metal stent
}

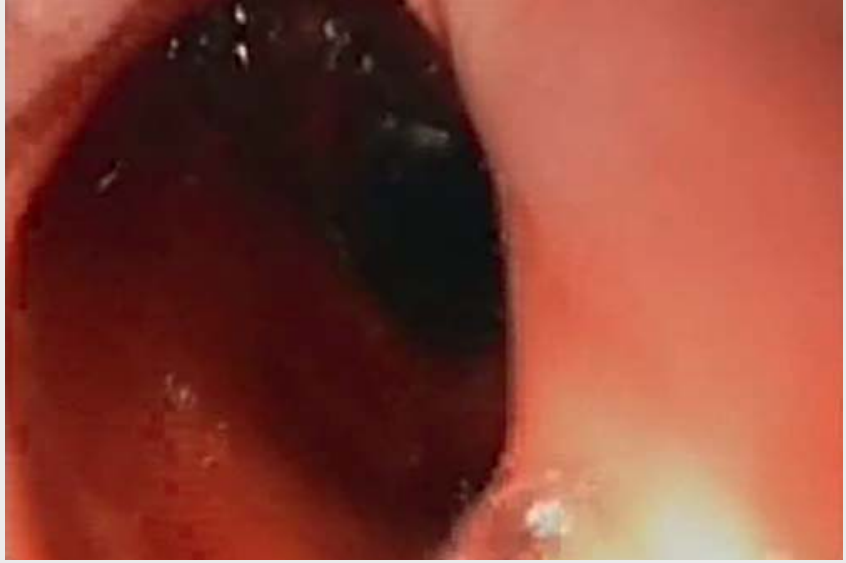

Video 1 latrogenic pharyngoesophageal perforation treated with a fully covered selfexpandable metal stent and orotracheal intubation.

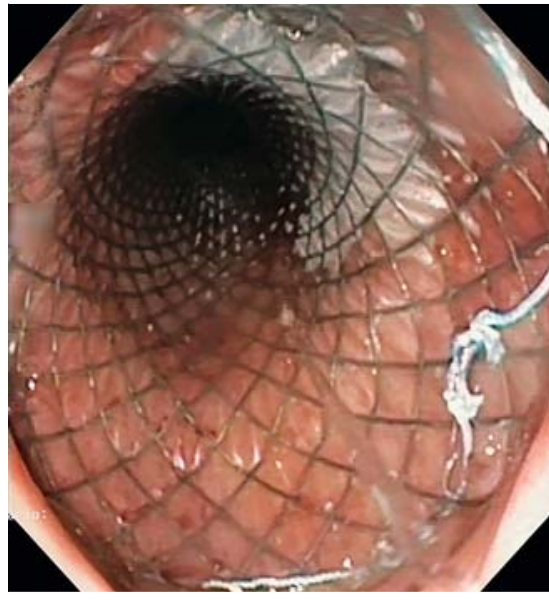

- Fig. 1 A fully covered self-expandable metal stent was placed at the site of the pharyngoesophageal perforation.

A 69-year-old woman with a history of renal transplantation was investigated for biliary duct dilation. She was receiving treatment with prednisone and tacrolimus.

Echoendoscopy was performed with a radial scope (Olympus GF-UE160) with the patient under conscious sedation.
During introduction of the endoscope, perforation was observed in the pharyngoesophageal area. The decision was made to place a fully covered self-expandable metal stent $(23 \times 12 \mathrm{~mm}$; Wallflex, Boston Scientific), completely covering the defect in the oropharynx ( Fig. 1). The patient was intubated first to avoid the discomfort caused by the stent, and was then moved to the resuscitation unit. The stent was removed 5 days later with apparent resolution of the perforation. Computed tomography (CT) and a barium esophagogram confirmed resolution of the defect (> Fig. 2; $>$ Fig.3). A small fluid collection at the mediastinum without air bubbles, shown on CT ( Fig.2), was treated conservatively with antibiotics ( $\$$ Video $\mathbf{1}$ ). The patient recovered completely with no symptoms of dysphagia.

latrogenic oropharyngeal perforation is a rare complication of echoendoscopy, occurring in $0.03 \%$ of explorations [ 1,2$]$. The rate is probably higher with echoendoscopes and duodenoscopes because of their rigidity and lateral or oblique viewing. In the oropharynx, it is not possi-

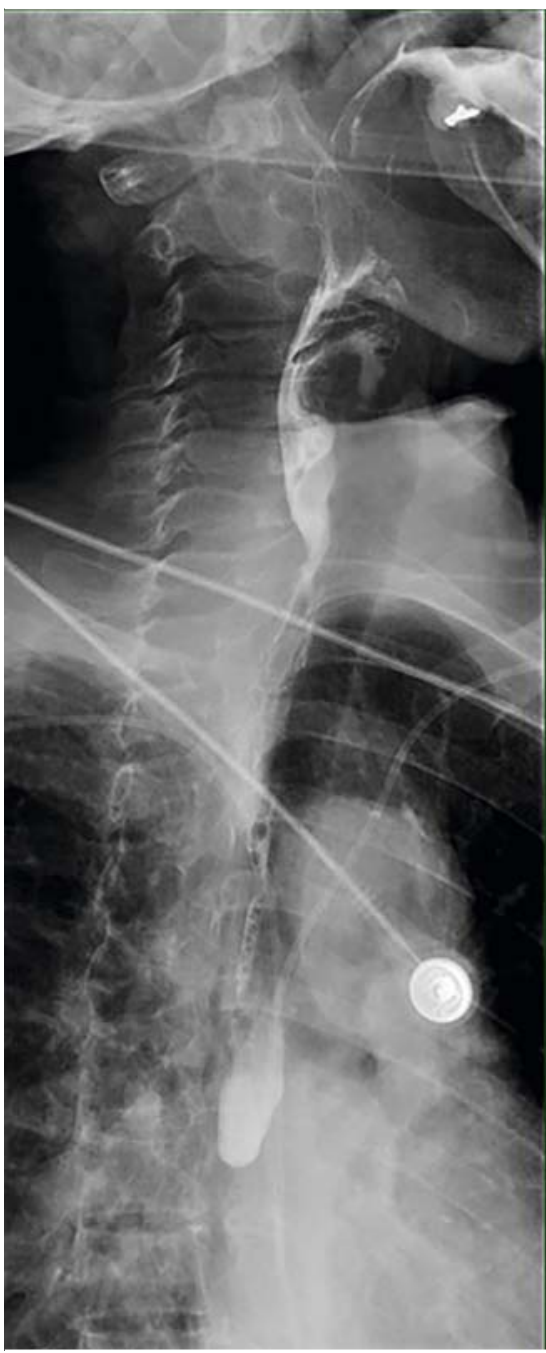

- Fig. 2 A barium esophagogram showed no perforation after stent retrieval.

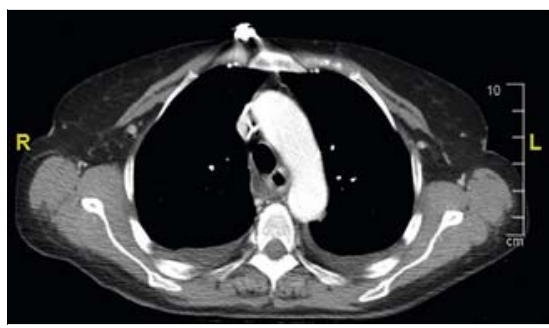

- Fig. 3 Computed tomography showed a small collection at the mediastinum, with no air bubbles. 
ble to close a perforation with either normal or over-the-scope clips. Other cases have been published in which resolution of the defect in 3 days was reported $[3,4]$, but because our patient was being treated with prednisone, we preferred to delay removal of the stent.

Endoscopy_UCTN_Code_CPL_1AL_2AG

Competing interests

The authors declare that they have no conflict of interest.

The authors

Ignacio Couto-Worner ${ }^{1} \odot$, Germán CharqueroMartínez ${ }^{2}$, José Souto-Ruzo ${ }^{1}$, Emilio EstévezPrieto $^{1}$, Benito González-Conde ${ }^{1}$, Pedro Alonso-Aguirre ${ }^{1}$

1 Complexo Hospitalario Universitario de A Coruña, A Coruña, Spain

2 Hospital Pasteur, Montevideo, Uruguay
Corresponding author

\section{Ignacio Couto-Worner, MD}

CHU A Coruña. As Xubias, 84. 15006,

A Coruña, Spain

Ignacio.couto.worner@sergas.es

\section{References}

[1] Das A, Sivak MV Jr, Chak A. Cervical esophageal perforation during EUS: a national survey. Gastrointest Endosc 2001; 53: 599-602

[2] Eloubeidi MA, Tamhane A, Lopes TL et al. Cervical esophageal perforations at the time of endoscopic ultrasound: a prospective evaluation of frequency, outcomes, and patient management. Am J Gastroenterol 2009; 104: 53-56

[3] Kumbhari V, Azola AA, Tieu AH et al. latrogenic pharyngoesophageal perforations treated with fully covered self-expandable metallic stents (with video). Surg Endosc 2015; 29: 987-991

[4] Mosquera-Klinger G, Torres Rincon R. Iatrogenic pharyngoesophageal perforations treated with fully covered self-expandable metal stents: Case report. Gastroenterol Hepatol 2019; 42: 429-430
Bibliography

Endoscopy 2021; 53: E431-E432

DOI 10.1055/a-1328-2330

ISSN 0013-726X

published online 27.1.2021

(c) 2021. Thieme. All rights reserved.

Georg Thieme Verlag KG, Rüdigerstraße 14,

70469 Stuttgart, Germany

\section{ENDOSCOPY E-VIDEOS}

https:/|eref.thieme.de/e-videos

回的 Endoscopy E-Videos is a free

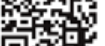
access online section, reporting on interesting cases and new

techniques in gastroenterological endoscopy. All papers include a high quality video and all contributions are freely accessible online.

This section has its own submission website at

https://mc.manuscriptcentral.com/e-videos 